American Journal of Applied Sciences 7 (11): 1464-1469, 2010

ISSN 1546-9239

(C) 2010 Science Publications

\title{
Benchmarking in the Academic Departments using Data Envelopment Analysis
}

\author{
${ }^{1}$ Mohammad Mahallati Rayeni and ${ }^{2}$ Faranak Hosseinzadeh Saljooghi \\ ${ }^{1}$ Department of Management, Technological Institution of Bahonar, Zahedan, Iran \\ ${ }^{2}$ Department of Mathematics, University of Sistan and Baluchestan, Zahedan, Iran
}

\begin{abstract}
Problem statement: The purpose of this study is to analyze efficiency and benchmarking using Data Envelopment Analysis (DEA) in departments of University. Benchmarking is a process of defining valid measures of performance comparison among peer decision making units (DMUs), using them to determine the relative positions of the peer DMUs and, ultimately, establishing a standard of excellence. Approach: DEA can be regarded as a benchmarking tool, because the frontier identified can be regarded as an empirical standard of excellence. Once the frontier is established, then one may compare a set of DMUs to the frontier. Results: We apply benchmarking to detect mistakes of inefficient departments to become efficient and to learn better managerial practice. Conclusion: The results indicated 9 departments are inefficient between 21 departments. The average inefficiency is 0.8516. Inefficient departments don't have excess in the number of teaching staff, but all of them have excess the number of registered student. The shortage of performed research works is the most important indicators of outputs in inefficient departments, which must be corrected.
\end{abstract}

Key words: Data Envelopment Analysis (DEA), performance assessment, benchmarking process, Decision Tree (DT), marketing productivity, Decision Making Units (DMUs), Linear Programming (LP), fractional program

\section{INTRODUCTION}

Benchmarking has not received much attention in Academic department of universities, because of the lack of appropriate methodological tools to aid the benchmarking process. The main benchmarking methods can be classified as either average or frontieroriented (Jamasb and Pollitt, 2001; Anwarul Huq and Arshad, 2010). The former compares firms against some average level of performance, while the latter measures their performance against an efficient frontier or best practice. The average-based methods lend themselves to the notion of yardstick regulation first proposed in Shleifer (1985). The main average-based methods are ordinary least squares and total factor productivity. The most widely used frontier-based techniques are DEA and stochastic frontier analysis. Data Envelopment Analysis (DEA) is suggested to aid traditional benchmarking activities and to provide guidance to managers (Cooper et al., 2007). DEA is useful in identifying the best performing units to be benchmarked against as well as in providing actionable measures for improvement of a company's performance. DEA constructs the best performance "frontier" and reveals the relative shortcomings of inefficient Decision-Making Units (DMUs). The frontier is the boundary of the convex hull of the set of efficient observations in input/output space, causes a mathematical programming model to estimate best practice frontiers without a priori underlying functional form assumption through computing multi-input/ multioutput values. Since the first CCR, DEA model was put forward by Charnes et al. (1978), a number of different DEA models and their corresponding realworld applications have appeared in literatures (Cooper et al., 2007; Azadeh et al., 2008; Chen et al., 2010). The major advantage of the DEA approach is that DEA does not require any assumptions about the function form. The performance measure of a multiple inputs and multiple outputs production system can hardly be described by a concrete function form. Therefore, DEA is particularly suitable for analyzing multiple inputs and multiple outputs production systems. Thus there is a high potential for DEA applications, DEA has been widely used in different industrial sectors in the area of industrial management for performance evaluation and benchmarking studies. DEA has been applied in many sectors (education,

Corresponding Author: Mohammad Mahallati Rayeni, Department of Management, Technological Institution of Bahonar, Zahedan, Iran 
health care, finance, utilities). The knowledge of the internal structure of the Decision Making Units (DMUs) might give further insights for their performance evaluation (Mahallati Rayeni and Saljooghi, 2010).

Cook et al. (2004) developed a set of DEA-based benchmark models. Donthu et al. (2004) investigated rigorous quantitative approach to benchmarking marketing productivity also Seol et al. (2007) used the integrated form of DEA and Decision Tree (DT) as a benchmarking method.

In this study, we present a DEA-based benchmarking method where each DMU is evaluated against a set of given benchmarks and apply it for benchmarking the universities.

The remainder of this study is as follows. First, we introduce a brief summary benchmarking process based on previous work in operations management research. Then, we investigate DEA as an appropriate methodology for benchmarking as well as extending current uses of DEA, and present DEA-based benchmark for the academic departments' university. Finally, we discuss our findings and implications for managers and researchers.

\section{MATERIALS AND METHODS}

Benchmarking analysis: A benchmarking analysis normally includes the selection of methods aiming at answering the following three questions: How is best practice or other norms properly determined in a specific analysis? What characterises best practice? How much and in which way does each organisation deviate from the norm?

Benchmarks for performance evaluation need not reflect best practice, but could be chosen arbitrarily as performance goals in a regulation process.

Benchmarking experts suggest multistep approaches to the process of benchmarking (Camp, 1998; Spendolini, 1992). There are three basic steps of benchmarking that analysts agree on:

- Identify the best performers

- Set benchmarking goals

- Implementation

The first step entails identifying a DMU (or set of DMUs) that is acknowledged as the best performer. At second step, DMUs measure their own efficiency and the efficiency of the best performers. The third step, implementation of best practices, has been the point of focus for most DMUs that engage in benchmarking. Implementation involves effecting business practices in order to emulate competitors that have the best performance.
Methodology of benchmarking should be able to identify a specific best-performing peer group to be used as a comparison group and it should be able to assist managers in setting goals in specific areas. A benchmarking tool should have the ability to analyze multiple inputs and multiple outputs that may comprise efficiency and provide feedback concerning areas for needed improvement. However, in order to be managerially relevant, a benchmarking technique should provide a single measure of overall efficiency that can be computed for every DMU and compared with competitors. At first we give a brief review of DEA and demonstrate how DEA can be used in the benchmarking processes.

DEA and benchmarking: Data Envelopment Analysis (DEA) has been recognized as an excellent method for analyzing performance and modeling organizations and operational processes, particularly when market prices are unavailable. Unlike the statistical regression method that tries to fit a regression plane through the center of the data, DEA floats a piecewise linear surface to rest on top of the data by linear programming techniques (Cooper et al., 2007). DEA, on the other hand, produces an efficient frontier consisting of the set of most efficient performers, allowing a direct comparison to the best performers. But, the statistical regression method estimates the parameters in the assumed functional form by a single optimization over all Decision Making Units (DMUs) whereas DEA uses optimizations for different DMUs without a priori assumptions on the underlying functional forms. Because of this unique feature, DEA has been applied to various areas of efficiency evaluation. In DEA, the ratio of weighted outputs and inputs produces a single measure of productivity called relative efficiency. Let there be $n$ DMUs whose efficiencies have to be compared. Let us take one of the DMUs, say the kth DMU and maximize its efficiency according to the formula given following:

$$
\begin{aligned}
& \operatorname{Maximize} \mathrm{h}_{\mathrm{o}}=\frac{\sum_{\mathrm{r}=1}^{\mathrm{s}} \mathrm{u}_{\mathrm{r}} \mathrm{y}_{\mathrm{rk}}}{\sum_{\mathrm{i}=1}^{\mathrm{m}} \mathrm{v}_{\mathrm{i}} \mathrm{x}_{\mathrm{ik}}} \\
& \text { Subject to } \frac{\sum_{\mathrm{r}=1}^{\mathrm{s}} \mathrm{u}_{\mathrm{r}} \mathrm{y}_{\mathrm{rj}}}{\sum_{\mathrm{i}=1}^{\mathrm{m}} \mathrm{v}_{\mathrm{i}} \mathrm{x}_{\mathrm{ij}}} \leq 1 \quad \mathrm{j}=1,2, \ldots ., \mathrm{n} \\
& \mathrm{u}_{\mathrm{r}} \geq 0 \quad \mathrm{r}=1, \ldots, \mathrm{s} \\
& \mathrm{v}_{\mathrm{i}} \geq 0 \quad \mathrm{i}=1, \ldots, \mathrm{m}
\end{aligned}
$$


Where:

$\mathrm{h}_{\mathrm{k}} \quad=$ The efficiency of the kth DMU

$\mathrm{y}_{\mathrm{rj}} \quad=$ rth output of the jth DMU

$\mathrm{u}_{\mathrm{r}} \quad=$ The weight of that output

$\mathrm{x}_{\mathrm{ij}} \quad=$ ith input of the jth DMU

$\mathrm{v}_{\mathrm{i}} \quad=$ The weight of that input, $\mathrm{j}=1,2, \ldots, \mathrm{n}$

$\mathrm{y}_{\mathrm{rk}}$ and $\mathrm{x}_{\mathrm{ik}}=\mathrm{rth}$ output and ith input, respectively, of the kth DMU. Note that here $\mathrm{n}$ includes $\mathrm{k}$

DMUs that have a ratio of 1 are referred to as efficient and lie on the frontier. The DMUs on the efficiency frontier are the best performing peers that need to be emulated. Hence, the first step in benchmarking is achieved by using the DMUs on the frontier.

The units that have a ratio less than 1 are lessefficient relative to the most efficient unit. A DMU that is not efficient and is inside the frontier can choose efficient DMUs on the frontier and selected efficient DMUs is named its reference set. Hence, depending on the size and scope of a DMU, each DMU will have a different set of reference set.

Note that model (1) is fractional program. It is generally difficult to solve fractional program. It can be converted to Linear Programming (LP) format and then they can be solved easily. The simplest way to convert this fractional program to linear program is to normalize the denominator of the fractional programming objective function; with this variation, model (1) convert to linear model (2).

$$
\begin{aligned}
& \text { Maximize } \mathrm{h}_{\mathrm{k}}=\sum_{\mathrm{r}=1}^{\mathrm{s}} \mathrm{u}_{\mathrm{r}} \mathrm{y}_{\mathrm{rk}} \\
& \text { Subject to } \sum_{r=1}^{s} u_{r} y_{r j}-\sum_{i=1}^{m} v_{i} x_{i j} \leq 0 j=1,2, \ldots ., n \\
& \sum_{i=1}^{m} v_{i} x_{i k}=1 \\
& \mathrm{u}_{\mathrm{r}} \geq 0 \quad \mathrm{r}=1,2 \ldots, \mathrm{s} \\
& \mathrm{v}_{\mathrm{i}} \geq 0 \quad \mathrm{i}=1,2 \ldots, \mathrm{m}
\end{aligned}
$$

If we present optimal solution of model (2) as $\left(\mathrm{h}_{\mathrm{k}}{ }^{*}\right.$, $\left.\mathrm{v}^{*}, \mathrm{u}^{*}\right)$ then $\mathrm{DMU}_{\mathrm{k}}$ is efficient if $\mathrm{h}_{\mathrm{k}}{ }^{*}=1$ and there exists at least one optimal $\left(\mathrm{v}^{*}, \mathrm{u}^{*}\right)$, with $\mathrm{v}^{*}>0$ and $\mathrm{u}^{*}>0$. Otherwise, $\mathrm{DMU}_{\mathrm{k}}$ is inefficient.

The distance between a DMU and the frontier provide the goals for benchmarking. A unit can become efficient by moving towards the frontier by reduce inputs or increase outputs produced or a combination of both. Since efficiency is the ratio of output to input, a DMU can become efficient by increasing output or decreasing input. Such measurable and actionable goals satisfy the requirements of step 2 of the benchmarking process. In other words, a DMU becomes efficient by moving towards the frontier.

Having identified the reference set and the areas for needed improvement, step 3 of the benchmarking process, implementing benchmarking, can be done. Management can evaluate the operations of the peer group units or reference set to determine what changes in inefficient unit can be made.

\section{RESULTS}

DEA-based benchmarking in university: To evaluate educational system cannot be used of market evaluation mechanisms such as benefit assessment to determine DMU performance or inputs and outputs economic value, because inputs and outputs generally stand in the education, research and service departments which the measurement or presentation of an assessment unit is very difficult. DEA method also emphasizes university targets for inputs and outputs choice and makes possible the choice of qualities input and output indicators to the system.

In this article, the $\mathrm{S}$ and $\mathrm{B}$ University's educational departments are viewed as DMUs. Input and output variables were chosen after consultation with the management. Input variables included the number of registered student $\left(\mathrm{x}_{1}\right)$ and the number of teaching staff $\left(\mathrm{x}_{2}\right)$. Three output variables were selected to represent both teaching and research outcomes: the number of graduates $\left(\mathrm{y}_{1}\right)$, the number of passed students to higher levels $\left(\mathrm{y}_{2}\right)$ and the performed research work $\left(\mathrm{y}_{3}\right)$. Our original data consist of the annual statistics for the year 2009 collected in each of the 21 departments of the university. From these data the outputs and inputs are as shown in Table 1.

We performed the DEA analysis using the software program DEA-Solver. Table 2 is a summary of the efficiency scores, ranking and the reference set computed by DEA. These efficiency scores represent the best possible efficiency attainable by a DMU given its inputs and outputs and comparing it to the inputs and outputs of the remaining DMUs. 
Am. J. Applied Sci., 7 (11): 1464-1469, 2010

Table 1: The gathered information to assess educational departments of Sistan and Baluchestan, Academic year 2008-2009

\begin{tabular}{lrrrrr}
\hline Education department & $\mathrm{x}_{1}$ & $\mathrm{x}_{2}$ & $\mathrm{y}_{1}$ & $\mathrm{y}_{2}$ & \multicolumn{1}{c}{$\mathrm{y}_{3}$} \\
\hline Civil & 695 & 20 & 125 & 14 & 230 \\
Material & 420 & 8 & 83 & 10 & 95 \\
Mechanics & 610 & 15 & 101 & 15 & 205 \\
Chemistry & 745 & 40 & 115 & 30 & 320 \\
Electronics & 1150 & 18 & 132 & 25 & 110 \\
Computer & 525 & 8 & 81 & 10 & 95 \\
Management & 890 & 16 & 135 & 26 & 150 \\
Economics & 825 & 14 & 140 & 18 & 165 \\
Persian literature & 693 & 15 & 122 & 22 & 145 \\
Geography & 610 & 18 & 121 & 25 & 190 \\
English & 520 & 14 & 109 & 14 & 205 \\
History & 592 & 17 & 99 & 19 & 155 \\
Psychology & 752 & 18 & 118 & 22 & 175 \\
Physics & 595 & 20 & 101 & 13 & 195 \\
Biologics & 495 & 18 & 115 & 18 & 210 \\
Law & 560 & 10 & 122 & 17 & 190 \\
Accountancy & 750 & 8 & 128 & 13 & 125 \\
Industrial & 425 & 6 & 80 & 8 & 95 \\
Islamic knowledge & 694 & 16 & 101 & 20 & 160 \\
Arabic language & 742 & 15 & 115 & 17 & 170 \\
Mathematics & 1250 & 23 & 121 & 19 & 270 \\
\hline
\end{tabular}

\section{DISCUSSION}

In results Table 2, the departments that have an efficiency score of 1.0 are considered to be efficient and hence lie on the efficiency frontier. In this case, we have 12 departments that are efficient and9 that are inefficient. DEA allows us to take one step further and identify a smaller group of best performers specific to the characteristics of an individual department (based on the weights given to the inputs and outputs).

Arabic language department is the least efficient unit (efficiency $=0.731$ ). In order to identify its reference set of benchmarking targets, we use DEA. The efficient units identified by DEA analysis (Table 2) are units Material, Geography, Law and Biologics. Therefore, for Arabic language department to become efficient, it would have to emulate those four units. This addresses step one in the benchmarking, identifying the peer group. Step 2, setting benchmarking goals, is also handled well through DEA analysis. DEA calculates slacks which specify the amount by which an input or output must be improved in order for the unit to become efficient. The nonzero slacks and/or the value of (efficiency score $<1$ ) identify the sources and amounts of inefficiency in each input and output of the DMU being evaluated. The efficiency of DMU can be improved if the input values are reduced by the ratio "efficiency score" and the input excesses recorded in "input slack" are eliminated. Similarly efficiency can be attained if the output values are augmented by the output shortfalls in "output slack".
Table 2: Efficiency score, Ranking and Reference set of departments

\begin{tabular}{llrl}
\hline DMU & Score & Rank & Reference set \\
\hline Civil & 1.000 & 1 & Civil \\
Material & 1.000 & 1 & Material \\
Mechanics & 0.911 & 14 & Chemistry- English - law- \\
& & & Mathematics \\
Chemistry & 1.000 & 1 & Chemistry \\
Electronics & 0.852 & 17 & Management-law \\
Computer & 0.865 & 16 & Material-law-industrial \\
Management & 1.000 & 1 & Management \\
Economics & 1.000 & 1 & Economics \\
Persian literature & 0.951 & 13 & Management-law-geography \\
Geography & 1.000 & 1 & Geography \\
English & 1.000 & 1 & English \\
History & 0.891 & 15 & Material-geography-biologics \\
Psychology & 0.818 & 19 & Management-geography-law \\
Physics & 0.817 & 20 & English-biologics-industrial \\
Biologics & 1.000 & 1 & Biologics \\
Law & 1.000 & 1 & Law \\
Accountancy & 1.000 & 1 & Accountancy \\
Industrial & 1.000 & 1 & Industrial \\
Islamic knowledge & 0.827 & 18 & Material-geography-law \\
Arabic language & 0.731 & 21 & Material-geography-law-biologics \\
Mathematics & 1.000 & 1 & Mathematics \\
\hline
\end{tabular}

In the case of inefficient Arabic language department, we see that there are one output slacks, research work. In order for this department to become efficient, it must add work research by 3.832 (Table 3), also this unit does not have slacks in the inputs, therefore it must reduce both inputs (the number of registered student and the number of teaching staff) by the ratio 0.731 .

Step 3 of the benchmarking process, implementing benchmarking, can now be done through the traditional means. Arabic language department can be efficient if it increase third output, that is, it should encourage its scientific board to more research works and reduce the number of registered student and the number of teaching staff to 542.34 and 10.96 , respectively (Table 3 and 4). For more illustration, consider Electronics department. Efficiency of this department is 0.852 and its reference set is departments of Management and Law. We see that there are one input slack and two output slacks. In order for Electronics department to become efficient, it must cut the number of registered student by 126.3 , while maintaining its current level of second output and add first and third outputs to 1.555 and 44.444, respectively. Therefore, this department must decrease the number of registered student 25.8 percent, while it increase the number of graduates and the performed research work 1.18 and $40.4 \%$, respectively, also retain the number of passed students in its current level ( Tables 3 and 4).

Given that it may not be realistic to achieve this goal of cutting input while maintaining or increasing outputs, one may sometimes not be able to fully implement benchmarking. In other words, a DMU may never become completely efficient. 
Am. J. Applied Sci., 7 (11): 1464-1469, 2010

Table 3: The values of slack of inputs and outputs

\begin{tabular}{|c|c|c|c|c|c|c|}
\hline DMU & Score & $\begin{array}{l}\text { Excess } \\
\text { Input } x_{1}\end{array}$ & $\begin{array}{l}\text { Excess } \\
\text { Input } x_{2}\end{array}$ & $\begin{array}{l}\text { Shortage } \\
\text { Output } y_{1}\end{array}$ & $\begin{array}{l}\text { Shortage } \\
\text { Output } y_{2}\end{array}$ & $\begin{array}{l}\text { Shortage } \\
\text { Output } y_{3}\end{array}$ \\
\hline Civil & 1.000 & 0.000 & 0 & 0.0000 & 0.0000 & 0.000 \\
\hline Material & 1.000 & 0.000 & 0 & 0.0000 & 0.0000 & 0.000 \\
\hline Mechanics & 0.911 & 0.000 & 0 & 11.3730 & 0.0000 & 0.000 \\
\hline Chemistry & 1.000 & 0.000 & 0 & 0.0000 & 0.0000 & 0.000 \\
\hline Electronics & 0.852 & 126.296 & 0 & 1.5550 & 0.0000 & 44.444 \\
\hline Computer & 0.865 & 0.000 & 0 & 8.1621 & 0.0000 & 20.540 \\
\hline Management & 1.000 & 0.000 & 0 & 0.0000 & 0.0000 & 0.000 \\
\hline Economics & 1.000 & 0.000 & 0 & 0.0000 & 0.0000 & 0.000 \\
\hline Persian literature & 0.951 & 0.000 & 0 & 2.8600 & 0.0000 & 35.130 \\
\hline Geography & 1.000 & 0.000 & 0 & 0.0000 & 0.0000 & 0.000 \\
\hline English & 1.000 & 0.000 & 0 & 0.0000 & 0.0000 & 0.000 \\
\hline History & 0.891 & 0.000 & 0 & 9.6870 & 0.0000 & 12.831 \\
\hline Psychology & 0.818 & 0.000 & 0 & 4.6280 & 0.0000 & 11.450 \\
\hline Physics & 0.818 & 0.000 & 0 & 9.3300 & 3.6125 & 0.000 \\
\hline Biologics & 1.000 & 0.000 & 0 & 0.0000 & 0.0000 & 0.000 \\
\hline Law & 1.000 & 0.000 & 0 & 0.0000 & 0.0000 & 0.000 \\
\hline Accountancy & 1.000 & 0.000 & 0 & 0.0000 & 0.0000 & 0.000 \\
\hline Industrial & 1.000 & 0.000 & 0 & 0.0000 & 0.0000 & 0.000 \\
\hline Islamic knowledge & 0.827 & 0.000 & 0 & 18.7310 & 0.0000 & 25.487 \\
\hline Arabic language & 0.731 & 0.000 & 0 & 0.0000 & 0.0000 & 3.832 \\
\hline Mathematics & 1.000 & 0.000 & 0 & 0.0000 & 0.0000 & 0.000 \\
\hline
\end{tabular}

Table 4: The changed values of inputs and outputs for attaining to efficiency

\begin{tabular}{|c|c|c|c|c|c|c|}
\hline & \multicolumn{3}{|c|}{ Electronics (0.852) } & \multicolumn{3}{|c|}{ Arabic language (0.731) } \\
\hline & Current value & New value & Percent of change & Current value & New value & Percent of change \\
\hline$\overline{\text { Input }\left(\mathrm{x}_{1}\right)}$ & 1150 & 853.3 & -25.80 & 742 & 542.3 & -26.91 \\
\hline Input $\left(\mathrm{x}_{2}\right)$ & 18 & 15.3 & -14.81 & 15 & 11.0 & -26.91 \\
\hline Output $\left(\mathrm{y}_{1}\right)$ & 132 & 133.5 & 1.18 & 115 & 115.0 & 0.00 \\
\hline Output $\left(\mathrm{y}_{2}\right)$ & 25 & 25.0 & 0.00 & 17 & 17.0 & 0.00 \\
\hline Output $\left(\mathrm{y}_{3}\right)$ & 110 & 154.4 & 40.40 & 170 & 173.8 & 2.25 \\
\hline
\end{tabular}

\section{CONCLUSION}

This article discussed efficiency improvement and how to identify appropriate benchmarks for inefficient departments to imitate. We argue that the most relevant benchmark is the most similar efficient departments. The DEA-based benchmarking approach considers inefficiency as the result of a lack of knowledge or managerial ability and it isn't the result of a lack of motivation or effort. In these cases, efficiency improvements may be achieved if the inefficient department is able to learn better education production routines. Benchmarking is a common tool used by decision makings that want to improve their understanding of the most successful practices in their field. We investigated efficiency and benchmarking in S and B University, which has 21 departments. The results indicated 9 departments are inefficient. A department (Electronic) has input slack but all inefficient departments have output shortfalls (output slacks). The average of shortage three outputs are 7.4, 0.4 and 17.1, respectively. The most shortage is relevant the research works in inefficient departments.

\section{REFERENCES}

Anwarul Huq A.S.M. and F. M. Arshad, 2010. Technical Efficiency of Chili Production. Am. J. Applied $\quad$ Sci., $\quad 7$ : 185-190. http://www.scipub.org/fulltext/ajas/ajas72185-190.pdf

Azadeh, A., S.F. Ghaderi, Z. Javaheri and M. Saberi, 2008. A fuzzy mathematical programming approach to DEA models. Am. J. Applied Sci., 5: 1352-1357.

http://en.scientificcommons.org/34606307

Camp, R.C., 1998. Global cases in benchmarking. Milwaukee (WI) 7 ASQ Quality Press

Charnes, A., W.W. Cooper and E.L. Rhodes, 1978. Measuring the efficiency of decision making units. Eur. J. Oper. Res., 2: 429-444. http://www.imamu.edu.sa/Data/abstract/manageme nt/Measuring $\% 20$ the $\% 20$ efficiency $\% 20$ of $\% 20$ desc ision\%20making\%20units.pdf

Chen, T.H., C.P. Bao and C.M. Huang and I.C. Wang, 2010. Efficiency decomposition with enhancing Russell measure in data envelopment analysis. Am. J. Applied Sci., 7: 438-441. DOI: 10.3844/ajassp.2010.438.441 
Cook, W.D., L.M. Seiford and J. Zhu, 2004. Models for performance benchmarking: Measuring the effect of e-commerce activities on banking performance. Omega, 32: 313-322. DOI: 10.1016/j.omega.2004.01.001

Cooper, W.W., L.M. Seiford and K. Tone, 2007. Data envelopment analysis: A comprehensive text with models, applications, references and DEA-solver software. Boston: Kluwer Academic Publishers. http://www.amazon.com/Data-EnvelopmentAnalysis-ComprehensiveApplications/dp/0387452818

Donthu, N., E.K. Hershberger and T. Osmonbekov, 2004. Benchmarking marketing productivity using data envelopment analysis. J. Bus. Res., 58:14741482. DOI: $10.1016 /$ j.jbusres.2004.05.007

Jamasb, T. and M. Pollit, 2001. Benchmarking and regulation: international electricity experience. Utilities Policy, 9: 107-130. DOI: 10.1016/S09571787(01)00010-8
Mahallati Rayeni, M. and F.H. Saljooghi, 2010. Network data envelopment analysis model for estimating efficiency and productivity in universities. J. Comp. Sci., 6: 1235-1240. ISSN: 1549-3636

Seol, H., J. Choi, G. Park and Y. Park, 2007. A framework for benchmarking service process using data envelopment analysis and decision tree. Expert Syst. Appl., 32: 432-440. DOI: 10.1016/j.eswa.2005.12.012

Shleifer, A., 1985. A theory of yardstick competition. Rand J. Econ., 16: 319-327. http://www.economics.harvard.edu/faculty/shleifer/ papers/theory_yardstick_comp.pdf

Spendolini, M.J., 1992. The benchmarking book. New York American Management Association. http://books.google.com.pk/books?id=6HV4QgAA CAAJ\&dq=The+benchmarking+book\&hl=en\&ei= PNOOTYa0EYuSswaGh9X7DA\&sa=X\&oi=book result\&ct=result\&resnum=2\&ved=0CCkQ6AEwAQ 